\title{
PENERAPAN METODE REGRESI LOGISTIK BINER UNTUK MENGETAHUI DETERMINAN KESIAPSIAGAAN RUMAH TANGGA DALAM MENGHADAPI BENCANA ALAM
}

\author{
Studi Kasus di Provinsi Jawa Tengah Tahun 2017
}

\author{
(Application Of Binary Logistic Regression Method To Know The Determinant Of Household \\ Preparedness In Facing Natural Disasters)
}

\author{
Ayu Wulandari ${ }^{1}$, Fahrulraz M. Faruk², Fransiska Sisilia Doven ${ }^{3}$, Budyanra4, \\ ${ }^{1}$ Politeknik Statistika STIS \\ 2Politeknik Statistika STIS \\ ${ }^{3}$ Politeknik Statistika STIS \\ ${ }^{4}$ Politeknik Statistika STIS
}

Alamat: Jalan kebon nanas selatan I no 3 rt 003 rw 008, cipinang, cempedak, jatinegara, Jakarta timur E-mail: $16.9040 @$ stis.ac.id

\begin{abstract}
ABSTRAK
Kesiapsiagaan rumah tangga dalam menghadapi bencana alam penting untuk dilakukan secara efektif. Hal ini agar dampak negatif yang ditimbulkan dari bencana alam dapat diminimalisir. Penelitian ini bertujuan untuk mengetahui gambaran umum kesiapsiagaan rumah tangga dalam menghadapi bencana alam, dan variabel-variabel yang berpengaruh signifikan terhadap kesiapsiagaan. Karena variabel status kesiapsiagaan rumah tangga bersifat kategorik yang terdiri atas dua kategori, maka metode analisis yang digunakan adalah regresi logistik biner. Penelitian ini menggunakan data SUSENAS Kor Maret 2017. Hasil dari analisis deskriptif menunjukkan bahwa rumah tangga di Jawa Tengah masih belum sepenuhnya siap dalam menghadapi bencana alam. Hasil analisis regresi logistik biner menunjukkan bahwa variabel tingkat pendidikan kepala rumah tangga, pernah mengalami bencana alam, partisipasi kegiatan kemasyarakatan dan akses informasi berpengaruh signifkan terhadap kesiapsiagaan rumah tangga dalam menghadapi bencana alam di Jawa Tengah tahun 2017.
\end{abstract}

Kata kunci: Bencana Alam, Kesiapsiagaan, Rumah Tangga, Regresi Logistik Biner

\begin{abstract}
Household preparedness in the face of natural disasters is important to be carried out effectively. This is so that the negative impacts arising from natural disasters can be minimized. This study aims to determine the general picture of household preparedness in the face of natural disasters, and variables that have a significant effect on preparedness. Because the household preparedness status variable is categorized in two categories, the analytical method used is binary logistic regression. This study uses SUSENAS data in March March 2017. The results of the descriptive analysis show that households in Central Java are not fully prepared to face natural disasters. The results of the binary logistic regression analysis indicate that the variable level of education of household heads, having experienced natural disasters, participation in community activities and access to information significantly influence household preparedness in dealing with natural disasters in Central Java in 2017.
\end{abstract}

Keywords: Natural Disaster, Preparedness, Household, Binary Logistic Regression

\section{PENDAHULUAN}

Sejak tahun 1998 bencana alam yang terkait dengan iklim dan peristiwa geologi, telah menewaskan lebih dari 1,3 juta orang, serta meninggalkan 4,4 miliar lebih korban yang terluka, tunawisma, terlantar atau membutuhkan pertolongan darurat. Mayoritas dari korban jiwa disebabkan oleh peristiwa geologi, dimana sebagian besarnya berasal dari gempa bumi dan tsunami. Negara-negara yang dilanda oleh bencana, juga melaporkan kerugian ekonomi yang mencapai US\$2.908 miliar dan membuat kurang lebih 26 juta orang jatuh miskin setiap tahunnya (CRED \& UNISDR, 2017). Bencana alam dapat menghambat jalannya tujuan pembangunan 
berkelanjutan (sustainable development goals/SDGS) yang diantaranya terkait dengan pemberantasan kemiskinan dan peningkatan kesejahteraan.

Beberapa indikator di dalam SDGS, secara khusus membahas tentang pengurangan resiko bencana seperti membangun kota dan pemukiman yang aman dan tangguh, serta tindakan untuk memerangi perubahan iklim serta dampak-dampaknya. Hal ini karena secara langsung, bencana alam memiliki hubungan timbal balik dengan tujuan pembangunan berkelanjutan (SDG's). Sebuah bencana alam besar, baik itu gempa bumi, tsunami, dan tanah longsor, dapat menghambat maupun mengembalikan capaian pembangunan yang selama bertahun-tahun telah dilaksanakan. Disamping itu, pembangunan yang tidak berkelanjutan terutama yang berkaitan dengan faktor-faktor lingkungan dan ketahanan masyarakat, juga terkait langsung dengan peningkatan bencana maupun dampak/resiko dari bencana yang dihadapi (Uitto \& Shaw, 2016). Penanganan yang buruk terhadap perubahan iklim, serta ketahanan masyarakat yang tidak baik, dapat memperparah risiko maupun dampak dari bencana alam.

Kerangka Sendai yang dihasilkan pada Konferensi Dunia Ketiga PBB tentang Pengurangan Risiko Bencana di Jepang pada bulan Maret 2015, memiliki tujuh target strategis dan 38 indikator untuk mengukur kemajuan dalam mengurangi kerugian bencana. Indikator-indikator ini menyelaraskan implementasi Kerangka Sendai dengan Tujuan Pembangunan Berkelanjutan (SDG's) dan Perjanjian Paris tentang perubahan iklim (CRED \& UNISDR, 2017). Kerangka sendai lebih menekankan kepada manusia sebagai subjek bencana, dimana pendekatan yang lebih luas serta terpusat harus dilakukan. Target secara global dari kerangka Sendai dalam pengurangan resiko bencana diantaranya yaitu dengan mengurangi angka kematian akibat bencana serta jumlah orang terdampak.

Upaya pengurangan risiko bencana pada setiap negara tidak terlepas dari faktor-faktor sosialdemografis yang ada pada negara tersebut. Kondisi sosial dan demografis setiap negara yang berbeda-beda membuat upaya pengurangan risiko bencana pada masing-masing negara juga berbeda. Langkah-langkah yang berhasil mengurangi risiko di satu negara belum tentu berhasil di negara lainnya (ISDR, 2005).

Penanganan bencana yang sifatnya responsif tidak terlalu efektif untuk mengurangi risiko dari bencana. Ketika bencana alam terjadi, masyarakat akan tetap panik, karena kebanyakan dari mereka tidak tahu apa yang harus dilakukan dan bagaimana cara menyelamatkan diri dari bencana. Akibatnya, masih banyak masyarakat yang menjadi korban bencana. Oleh sebab itu, perubahan paradigma penanganan bencana dari respon terhadap bencana menjadi kesiapsiagaan dalam mengantisipasi bencana menjadi sangat krusial dan penting untuk dilakukan (Hidayati, 2008).

Kesiapsiagaan bencana dipandang sebagai langkah-langkah yang diambil sebelumnya untuk memastikan respon yang efektif terhadap dampak bahaya, diantaranya yaitu melalui sistem peringatan dini yang tepat waktu dan efektif serta evakuasi diri dan harta benda untuk sementara dari lokasi yang terancam (Affeltranger et al, 2007). Kesiapsiagaan penting sebagai sebuah proses dari manajemen pra bencana untuk meminimalisir dampak negatif dari bencana alam. Masyarakat harus tahu apa yang harus dilakukan ketika bencana alam terjadi.

\section{STUDI KASUS: Jawa Tengah, Indonesia}

Secara geografis wilayah Indonesia rawan untuk terjadi bencana alam. Indonesia berada diantara tiga lempeng besar dunia yaitu lempeng Eurasia di barat laut, lempeng Pasifik di utara, dan lempeng Indo-Australia di selatan. Aktifnya pergerakan ketiga lempeng ini menjadikan wilayah Indonesia rawan terjadi gempa bumi. Selain itu, Indonesia juga berada pada jalur Ring of Fire Pacific, yang menjadikannya daerah dengan gunung api aktif terbanyak di dunia. Ancaman ini tersebar di hampir seluruh wilayah Indonesia, membentang dari ujung pulau Sumatera sampai ke Papua (BNPB, 2018).

Jawa Tengah merupakan salah satu provinsi di Indonesia yang memiliki tingkat kerawanan bencana alam tinggi. Data Indeks Risiko Bencana Indonesia yang dikeluarkan oleh BNPB, menempatkan 22 kabupaten/kota di Provinsi Jawa Tengah sebagai wilayah dengan risiko bencana tinggi, sedangkan 13 kabupaten/kota berada pada risiko bencana sedang (BNPB, 2014). Selain itu, selama tahun 2008-2017, jumlah kejadian bencana alam di provinsi Jawa Tengah adalah yang terbanyak dibandingkan provinsi-provinsi lain dengan 4.292 kejadian yang menghasilkan korban jiwa yang cukup besar. 
Dengan tingkat kerawanan serta jumlah kejadian bencana alam yang tinggi, beberapa indikator kesiapsiagaan di Provinsi Jawa Tengah ternyata belum terlalu baik. Badan Pusat Statistik (BPS, 2014) mencatat bahwa hanya sekitar 17,48 persen rumah tangga yang mengetahui bagaimana cara menyelamatkan diri dari bencana. Begitu pula dengan persentase rumah tangga yang mengetahui sistem peringatan dini bencana yang hanya sebesar 11,62 persen.

Dengan tingkat kerawanan bencana alam tinggi, yang dibuktikan dengan jumlah kejadian bencana alam yang besar, seharusnya tingkat kesiapsiagaan rumah tangga dalam menghadapi bencana alam di provinsi Jawa Tengah harus lebih tinggi lagi. Karena apabila rumah tangga tidak siap dalam menghadapi bencana alam, maka potensi korban jiwa yang ditimbulkan akan sangat besar. Hal ini mengingat jumlah penduduk provinsi Jawa Tengah yang mencapai 34 juta orang.

Berkaitan permasalahan diatas, maka diperlukan penelitian tentang kesiapsiagaan rumah tangga dalam menghadapi bencana alam di provinsi Jawa Tengah. Penting bagi kita untuk meningkatkan pemahaman tentang faktor-faktor yang memengaruhi kesiapsiagaan rumah tangga. Tujuannya adalah untuk menemukan cara untuk menjangkau mereka yang rentan, sehingga dapat melindungi diri mereka sendiri merespons secara efisien (Brunie, 2007). Oleh karena itu, penelitian ini dilakukan dengan tujuan mendapatkan gambaran umum mengenai status kesiapsiagaan rumah tangga dalam menghadapi bencana alam beserta variabel-variabel yang memengaruhinya. Penelitian ini bertujuan untuk melihat perbandingan antara rumah tangga yang "siap" dan yang "tidak siap" dalam menghadapi bencana alam. Serta variabel-varibel apa sajakah yang secara signifikan berpengaruh terhadap status kesiapsiagaan rumah tangga kesiapsiasiagaan.

Terdapat beberapa penelitian terkait kesiapsiagaan rumah tangga dalam menghadapi bencana alam. LIPI-UNESCO/ISDR, (2006) merumuskan lima parameter untuk mengukur tingkat kesiapsiagaan masyarakat dalam menghadapi bencana alam. Lima parameter yang digunakan adalah pengetahuan dan sikap, kebijakan dan panduan, rencana tanggap darurat, sistem peringatan dini, dan mobilisasi sumber daya. Prasiska, (2017) dalam penelitiannya yang berjudul Mitigasi Bencana Alam pada Level Rumah Tangga di Indonesia Tahun 2014, menemukan hubungan yang signifikan antara tingkat pendidikan, pengalaman dalam menghadapi bencana alam, serta klasifikasi wilayah tempat tinggal dengan tingkat mitigasi pada level rumah tangga. Selain itu, Dokhi, et al. (2017) dalam penelitian mereka yang berjudul Social Capital and Disaster Preparedness in Indonesia, mencoba melihat pengaruh modal sosial terhadap tingkat kesiapsiagaan rumah tangga dalam menghadapi bencana alam di Indonesia. Variabel yang digunakan dalam penelitian ini adalah kepercayaan, toleransi, jaringan sosial, tindakan kolektif dan klasifikasi wilayah tempat tinggal. Hasil dari penelitian ini yaitu kelima variabel mempunyai pengaruh terhadap tingkat kesiapssiagaan rumah tangga dalam menghadapi bencana alam.

\section{METODE}

\section{Data}

Data yang digunakan dalam penelitian ini adalah data sekunder yang berasal dari raw data Survei Sosial Ekonomi Nasional (SUSENAS) modul Kor Maret tahun 2017 yang dilaksanakan oleh BPS. Unit analisis yang digunakan dalam penelitian ini sebanyak 1557 rumah tangga yang termasuk ke dalam wilayah rawan bencana alam di Provinsi Jawa Tengah.

\section{Definisi Operasional}

Berdasarkan Tabel 1. variabel dependen $(Y)$ didapat dari gabungan tiga indikator yaitu pengetahuan tentang cara menyelamatkan diri, pengetahuan tentang sistem peringatan dini, dan pengalaman mengikuti pelatihan/simulasi bencana. Masing-masing variabel memiliki skor 1 untuk kategori "iya" dan skor 0 untuk kategori "tidak". Variabel kesiapsiagaan didapat dari penjumlahan ketiga variabel tersebut, dimana menghasilkan skor paling kecil 0 dan skor terbesar 3. Dalam penelitian ini, total skor tersebut dikategorikan menjadi dua, yaitu total skor 2 dan 3 yang diberi kategori siap serta skor 0 dan 1 yang dikategorikan tidak siap. 
Tabel 1. Indikator penyusun variabel dependen.

Indikator

(1)

Tahu bagaimana cara menyelamatkan diri dari bencana alam

Mengetahui adanya tanda-tanda atau

peringatan untuk mengatasi kejadian darurat

bencana alam di lingkungan tempat tinggal

(seperti area tempat kumpul, petunjuk jalur

evakuasi, sirine pertanda bencana tsunami).

Anggota rumah tangga pernah mengikuti pelatihan/simulasi terkait bencana
Jawaban Kategori

(2)

(3)

$1=$ iya $\quad 1=$ siap

$0=$ tidak $\quad 0=$ tidak siap

Variabel Independen $(X)$ yang digunakan dalam penelitian ini adalah variabel karakteristik rumah tangga yang dapat dilihat pada Tabel 2.

Tabel 2. Ringkasan kategori variabel independen.

\begin{tabular}{ll}
\hline \multicolumn{1}{c}{ Variabel } & \multicolumn{1}{c}{ Kategori } \\
\hline \multicolumn{1}{c}{$(1)$} & \multicolumn{1}{c}{$(2)$} \\
\hline Tingkat Pendidikan KRT $(\mathrm{X} 1)$ & $1=$ tinggi, $0=$ rendah \\
\hline Jumlah art $(\mathrm{X} 2)$ & - \\
\hline Pernah mengalami bencana alam $(\mathrm{X} 3)$ & $1=$ iya, $0=$ tidak \\
\hline $\begin{array}{ll}\text { Partisipasi kegiatan kemasyarakatan } \\
(\mathrm{X} 4)\end{array}$ & $2=$ tinggi, $1=$ sedang, $0=$ rendah \\
\hline Klasifikasi wilayah tempat tinggal $(\mathrm{X} 5)$ & $1=$ perkotaan, $0=$ perdesaan \\
\hline Akses Informasi $(\mathrm{X} 6)$ & $1=$ baik, $0=$ tidak baik \\
\hline
\end{tabular}

\section{Metode Analisis}

Penelitian ini menggunakan dua metode analisis yaitu metode analisis deskriptif dan inferensia. Analsis deskriptif dilakukan untuk mendapatkan gambaran umum status kesiapsiagaan rumah tangga dengan menggunakan grafik. Analisis inferensia dilakukan untuk melihat variabel-variabel yang signifikan dalam memengaruhi status kesiapsiagaan rumah tangga dengan menggunakan metode Regresi Logistik Biner.

\section{Regresi Logistik Biner}

Regresi Logistik atau kadang-kadang disebut sebagai logit model, merupakan metode analisis yang digunakan untuk melihat hubungan anatara variabel dependen dan independen, dimana variabel dependennya bersifat kategorik. Terdapat dua model dalam analisis regresi logistik, yaitu regresi logistik biner dan regresi logistik multinomial. Regresi logistik biner digunakan apabila variabel dependen dari data bersifat dikotomi. Sedangkan apabila variabel dependen yang digunakan terdiri lebih dari dua kategori, maka model regresi logsitik yang tepat adalah regresi logistik multinomial (Ae, 2013).

Metode regresi logistik biner merupakan metode yang digunakan untuk menggambarkan hubungan satu atau lebih variabel independen terhadap variabel dependen. Variabel dependen yang digunakan berkategori diskrit dengan dua kemungkinan, yaitu sukses dan gagal. Kejadian sukses biasanya dinotasikan dengan $Y=1$, sedangkan kejadian gagal dinotasikan dengan $Y=0$ (Hosmer, 2000).

Tahapan yang dilakukan dalam regresi logistik biner adalah sebagai berikut:

1. Pembentukan model

Model regresi logistik yang akan terbentuk adalah sebagai berikut:

$g(x)=\beta 0+\beta 1 x 1+\beta 2 x 2+\beta 3 x 3+\beta 4 x 4 A+\beta 5 x 4 B+\beta 6 x 5+\beta 7 x 6$

keterangan:

$\mathrm{g}(\mathrm{x})=$ logit $\mathrm{n}(\mathrm{x})$

$\beta 0=$ estimasi parameter regresi

$\beta 1 \ldots \beta 7=$ estimasi nilai parameter atau koefisien regresi 
$\mathrm{x} 1 . . . \mathrm{x} 6$ = variabel independen

2. Pengujian Goodness of Fit

Uji Goodness of Fit digunakan untuk mengetahui bahwa model yang digunakan dalam penelitian telah sesuai dalam menjelaskan status kesiapsiagaan rumah tangga dalam menghadapi bencana alam. Hipotesis yang digunakan dalam uji tersebut adalah seperti berikut ini.

1. HO : Model yang dibentuk fit (Tidak terdapat perbedaan antara hasil observasi dan hasil prediksi model)

H1 : Model yang dibentuk tidak fit (Terdapat perbedaan antara hasil observasi dan hasil prediksi model)

2. Tingkat signifikansi $(a)=5$ persen

3. Statistik uji yang digunakan adalah statistik uji $C$

4. Keputusan tolak $\mathrm{HO}$ jika $\hat{C}>\times 20,05 ; 8$ atau p-value $<0,05$

5. Jika keputusan yang diperoleh tolak $\mathrm{HO}$,maka model yang terbentuk tidak sesuai dalam menjelaskan status kesiapsiagaan rumah tangga dalam menghadapi bencana alam. Oleh sebab itu, diharapkan hasil yang diperoleh dalam uji ini adalah gagal tolak $\mathrm{HO}$ yang mengartikan bahwa model yang digunakan telah sesuai dalam menjelaskan status kesiapsiagaan rumah tangga dalam menghadapi bencana alam.

3. Pengujian Parameter secara Simultan

Pengujian ini dilakukan unutk menguji secara simultan pengaruh variabel-variabel independen terhadap variabel dependen secara bersamaan dalam model dengan menghitung nilai statistik uji G. Hipotesis uji simultan adalah sebagai berikut.

1. $\mathrm{HO}: \beta 0=\beta 1=\beta 2=\beta 3=\beta 4=\beta 5=\beta 6=\beta 7=0$ ( Tidak ada pengaruh signifikan dari variabel independen secara simultan terhadap status kesiapsiagaan rumah tangga dalam menghadapi bencana alam )

$\mathrm{H} 1$ : minimal terdapat satu $\beta \mathrm{j} \neq 0$ ( Minimal terdapat satu variabel penjelas yang signifikan berpengaruh terhadap terhadap status kesiapsiagaan rumah tangga dalam menghadapi bencana alam)

$j=1,2,3,4,5,6,7$

2. Tingkat signifikansi $(a)=5$ persen

3. Statistik uji yang digunakan adalah uji $\mathrm{G}$

4. Keputusan tolak $\mathrm{H} 0$ jika $\mathrm{G}$ hitung $>X^{2} 0,05 ; 7$ atau $p$-value $<0,05$

5. Jika keputusan yang diperoleh adalah tolak $\mathrm{HO}$ dapat disimpulkan bahwa minimal terdapat satu variabel independen yang berpengaruh signifikan terhadap status kesiapsiagaan rumah tangga dalam menghadapi bencana alam.

4. Pengujian Parameter secara Parsial

Untuk mengetahui pengaruh dari tiap-tiap variabel independen terhadap variabel dependen, dilakukan pengujian secara parsial. Hipotesis yang digunakan adalah sebagai berikut.

1. $\mathrm{HO}: \beta \mathrm{j}=0$ (Tidak terdapat pengaruh signifikan antara variabel independen ke-j dengan status kesiapsiagaan rumah tangga dalam menghadapi bencana alam)

$\mathrm{H} 1: \beta \mathrm{j} \neq 0$ (Terdapat pengaruh signifikan antara variabel independen ke-j dengan status kesiapsiagaan rumah tangga dalam menghadapi bencana alam)

$\mathrm{j}=1,2,3,4,5,6$

2. Tingkat signifikasi $(a)=5$ persen

3. Statistik uji yan digunakan adalah statistik uji Wald

4. Kepurusan tolak $\mathrm{H} 0$ jika $\mathrm{W}>\mathrm{X}^{2} 0,05 ; 1$ atau nilai $p$-value $<0,05$

5. Jika keputusan yang diperoleh adalah tolak HO, dapat disimpulkan bahwa pada variabel independen ke-j secara parsial signifikan memengaruhi status kesiapsiagaan rumah tangga dalam menghadapi bencana alam di Jawa Tengah.

5. Rasio Kecendrungan (Odds Ratio)

Odds ratio merupakan suatu ukuran untuk melihat seberapa besar kecendrungan variabel independen terhadap variabel dependen. Variabel dependen dalam penelitian ini adalah status kesiapsiagaan rumah tangga dalam menghadapi bencana alam. Nilai odds ratio, yaitu nilai dari $\exp (\hat{\beta} \mathrm{j})$ pada variabel independen yang signifikan memengaruhi status kesiapsiagaan rumah tangga 
dalam menghadapi bencana alam. Nilai $\beta \hat{j}$ yang semakin besar mengindikasikan kecendrungan variabel independen terhadap status kesiapsiagaan juga semakin tinggi.

\section{HASIL DAN PEMBAHASAN}

\section{Analisis Deskriptif}

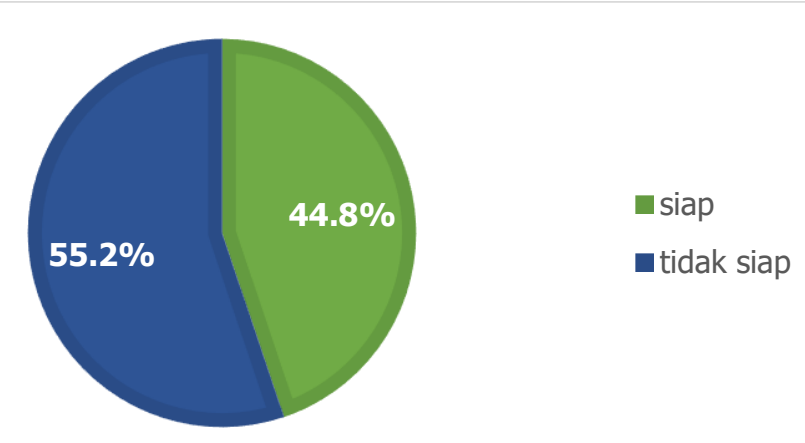

Sumber: SUSENAS KOR 2017 (diolah)

Gambar 1. Persentase rumah tangga berdasarkan status kesiapsiagaan rumah tangga dalam menghadapi bencana alam di Jawa Tengah tahun 2017.

Berdasarkan Gambar 1. dapat dilihat bahwa persentase rumah tangga yang siap dalam menghadapi bencana alam di Jawa Tengah adalah sebesar 44,8 persen, hal ini menunjukkan bahwa dari 100 rumah tangga, hanya 45 rumah tangga yang siap dalam menghadapi bencana alam.

Tabel 3. Presentase rumah tangga berdasarkan kategori variabel

\begin{tabular}{|c|c|c|c|}
\hline Variabel & Kategori & Presentase & Total \\
\hline \multirow{2}{*}{$\begin{array}{l}\text { Tingkat pendidikan } \\
\text { KRT }\end{array}$} & Rendah & 81,37 & \multirow[t]{2}{*}{100} \\
\hline & Tinggi & 18,63 & \\
\hline Jumlah ART & - & - & - \\
\hline \multirow{2}{*}{$\begin{array}{l}\text { Pernah mengalami } \\
\text { bencana alam }\end{array}$} & Tidak & 55,23 & \multirow[t]{2}{*}{100} \\
\hline & Ya & 44,77 & \\
\hline \multirow{3}{*}{$\begin{array}{l}\text { Partisipasi kegiatan } \\
\text { kemasyarakatan }\end{array}$} & Tidak pernah/kadang-kadang & 35,58 & \multirow{3}{*}{100} \\
\hline & Sering & 29,22 & \\
\hline & Selalu & 35,20 & \\
\hline \multirow{2}{*}{$\begin{array}{l}\text { Klasifikasi wilayah } \\
\text { tempat tinggal }\end{array}$} & Perdesaan & 54,98 & \multirow[t]{2}{*}{100} \\
\hline & Perkotaan & 45,02 & \\
\hline Akses Informasi & Tidak baik & 48,30 & 100 \\
\hline
\end{tabular}

Sumber: Data hasil pengolahan

Berdasarkan Tabel 3. variabel dengan selisih presentase diatas 50 persen adalah tingkat pendidikan KRT. Sedangkan sisanya mempunyai selisih presentase yang hampir sama. Dari tabel dapat dilihat bahwa rumah tangga pada wilayah rawan bencana alam, rata-rata memiliki kepala rumah tangga dengan pendidikan yang rendah. Rata-rata dari rumah tangga sudah mempunyai akses informasi yang baik serta memiliki presentase partisipasi kegiatan kemasyarakatan yang hampir sama pada setiap kategori Selain itu, sebagian besar rumah tangga juga bertempat tinggal di daerah perdesaan.

Tabel 4. Presentase rumah tangga berdasarkan status kesiapsiagaan rumah tangga dalam menghadapi bencana alam dan variabel independen kategorik.

\begin{tabular}{lcccc}
\hline \multirow{2}{*}{ Variabel } & Kategori & \multicolumn{2}{c}{ Status Kesiapsiagaan } & \multirow{2}{*}{ Total } \\
\cline { 2 - 4 } & & Tidak Siap & Siap & \\
\hline \multicolumn{1}{c}{$(1)$} & $(2)$ & $(3)$ & $(4)$ & $(5)$ \\
\hline $\begin{array}{l}\text { Tingkat Pendidikan KRT } \\
\text { (X1) }\end{array}$ & Rendah & 58,60 & 41,40 & 100 \\
\hline $\begin{array}{l}\text { Pengalaman mengalami } \\
\text { bencana alam (X3) }\end{array}$ & Tinggi & 40,30 & 59,70 & 100 \\
\hline & Tidak & 60,80 & 39,20 & 100 \\
\hline
\end{tabular}




\begin{tabular}{lcccc}
\hline $\begin{array}{l}\text { Partisipasi kegiatan } \\
\text { kemasyarakatan (X4) }\end{array}$ & Tidak pernah/kadang-kadang & 58,30 & 41,70 & 100 \\
\hline & Sering & 60,22 & 39,78 & 100 \\
\hline & Selalu & 47,81 & 52,19 & 100 \\
\hline $\begin{array}{l}\text { Klasifikasi Wilayah } \\
\text { Tempat Tinggal (X5) }\end{array}$ & Perdesaan & 60,16 & 39,84 & 100 \\
\hline \multicolumn{1}{c}{} & Perkotaan & 49,07 & 50,93 & 100 \\
\hline Akses Informasi (X6) & Tidak Baik & 61,70 & 38,30 & 100 \\
\hline Sumber: Data hasil pengolahan & Baik & 49,07 & 50,93 & 100 \\
\hline
\end{tabular}

Berdasarkan Tabel 4. secara deskriptif dapat dijelaskan bahwa rumah tangga dengan tingkat pendidikan kepala rumah tangga yang tinggi, memiliki akses informasi yang baik, tinggal di wilayah perkotaan, dan memiliki pengalaman dengan bencana alam, cenderung memiliki kesiapsiagaan yang lebih tinggi dalam menghadapi bencana alam. Selain itu, rumah tangga yang selalu berpartisipasi dalam kegiatan kemasyarakatan cenderung juga memiliki kesiapsiagaan yang lebih tinggi dibandingkan rumah tangga yang sering dan tidak pernah/kadang-kadang.

Sedangkan gambaran umum sebaran variabel jumlah anggota rumah tangga berdasarkan status kesiapsiagaan rumah tangga dalam menghadapi bencana alam dapat dilihat pada Gambar 2 .

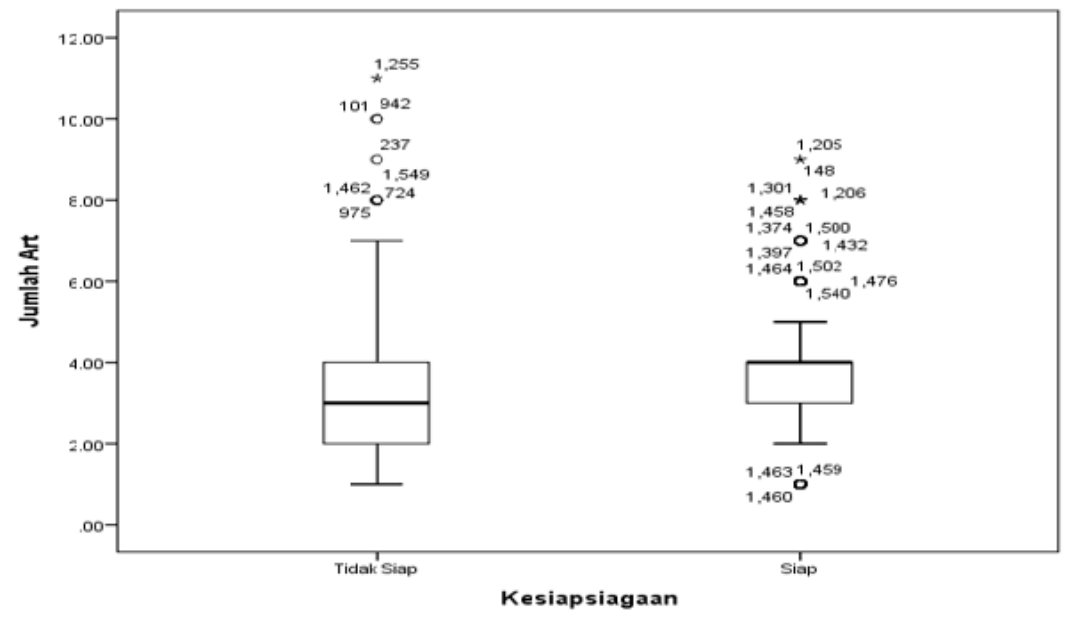

Sumber: SUSENAS KOR 2017 (diolah)

Gambar 2. Boxplot sebaran jumlah anggota rumah tangga berdasarkan status kesiapsiagaan rumah tangga dalam menghadapi bencana alam di Provinsi Jawa Tengah tahun 2017.

Gambar 2. menunjukkan bahwa pada umumnya rumah tangga yang siap menghadapi bencana alam di Provinsi Jawa Tengah memiliki jumlah anggota rumah tangga sebanyak empat orang, sedangkan untuk rumah tangga yang tidak siap memiliki anggota rumah tangga sebanyak tiga orang.

\section{Analisis Inferensia}

Persamaan regresi logistik biner yang terbentuk adalah sebagai berikut:

$$
\hat{\mathrm{g}}(X)=-0,794+0,554 X_{1}-0,035 X_{2}+0,448 X_{a}-0,045 X_{41}+0,422 X_{42}+0,187 X_{5}+0,345 X_{6}
$$

Keterangan:

$\mathrm{X}_{1} \quad$ : Variabel Tingkat Pendidikan KRT

$\mathrm{X}_{2} \quad$ : Variabel Jumlah Anggota Rumah Tangga

$\mathrm{X}_{3}$ : Variabel Pernah Mengalami Bencana Alam

$\mathrm{X}_{41}$ : Variabel Partisipasi Kegiatan Kemasyarakatan (sering)

$\mathrm{X}_{42}$ : Variabel Partisipasi Kegiatan Kemasyarakatan (selalu)

$\mathrm{X}_{5}$ : Variabel Klasifikasi Wilayah

$\mathrm{X}_{6}$ : Variabel Akses Informasi 


\section{Uji Kesesuaian Model (Goodness of Fit)}

Pada penelitian ini, analisis regresi logistik biner digunakan untuk mengetahui variabel-variabel yang memengaruhi status kesiapsiagaan rumah tangga dalam menghadapi bencana alam. Data penelitian yang diperoleh kemudian diolah menggunakan program SPSS. Sebelum analisis regresi logistik biner dilakukan, terlebih dahulu dilakukan uji kesesuaian model regeresi logistik yang digunakan dalam penelitian dengan menggunakan pengujian Hosmer and Lemeshow Goodness of Fit Test.

Tabel 5. Hasil Uji Hosmer and Lemeshow Goodness of Fit.

\begin{tabular}{ccc}
\hline Chi-square & Df & Sig \\
\hline$(1)$ & $(2)$ & $(3)$ \\
\hline 10,837 & 8 & 0,211 \\
\hline
\end{tabular}

Sumber: Output SPSS

Berdasarkan Tabel 5. di atas, nilai signifikansi chi-square adalah sebesar 0,211, lebih besar dibandingkan taraf siginifikansi 0,05 sehingga maka keputusan gagal tolak HO. Sehingga dapat disimpulkan bahwa dengan tingkat kepercayaan 95\% model regresi logistik yang digunakan sudah sesuai untuk menjelaskan status kesiapsiagaan rumah tangga dalam menghadapi bencana alam.

Selain dengan melihat uji Hosmer dan Lemeshow, kita juga dapat melihat dari hasil tabel klasifikasi. Dari hasil pengolahan pendugaan parameter didapatkan nilai overall percentage model adalah sebesar 59,4 persen. Angka tersebut menunjukkan bahwa secara keseluruhan, model yang digunakan mempunyai kemampuan dalam memprediksi status kesiapsiagaan rumah tangga dalam menghadapi bencana alam sebesar 59,4 persen.

\section{Pengujian Simultan}

Pengajuan penduga parameter secara simultan dilakukan dengan melihat hasil output dari pemerosesan data penelitian menggunakan bantuan SPSS, yaitu nilai uji G. Pengujian parameter secara simultan 'dilakukan untuk mengetahui pengaruh semua variabel independen dalam penelitian terhadap variabel dependen secara bersamaan. Hasil pengujian secara simultan diperoleh dari tabel Omnibus Test of Model Coeffcient, yaitu dengan membandingkan nilai statistik uji G dengan nilai $(0,05 ; 7)$.

Tabel 6. Output SPSS Omnimbus Test of Model Coefficient.

\begin{tabular}{cccc}
\hline & Chi-square & Df & Sig \\
\hline$(1)$ & $(2)$ & $(3)$ & $(4)$ \\
\hline Model & 85,650 & 7 & 0,000 \\
\hline
\end{tabular}

Sumber: Output SPSS

Tabel 6. menunjukan bahwa nilai signifikansi uji $\mathrm{G}$ adalah sebesar 0,000 lebih kecil dari tingkat signifikansi 0,05 . Sehingga keputusan yang diambil adalah tolak HO. Hal tersebut berarti terdapat minimal satu variabel independen yang dapat menjelaskan status kesiapsiagaan rumah tangga dalam menghadapi bencana alam di Jawa Tengah.

\section{Uji Parsial}

Berdasarkan hasil uji simultan, diketahui bahwa terdapat minimal satu variabel independen yang signifikan memengaruhi status kesiapsiagaan rumah tangga dalam menghadapi bencana alam di Provinsi Jawa Tengah tahun 2017. Tahap selanjutnya adalah melakukan pengujian secara parsial, untuk mengetahui seberapa banyak variabel independen yang mempunyai pengaruh signifikan terhadap status kesiapsiagaan rumah tangga dalam menghadapi bencana alam di Provinsi Jawa Tengah tahun 2017. Pengujian parsial dilakukan dengan statistik uji Wald. Hasil dari uji parsial dapat dilihat pada Tabel 7. berikut ini:

Tabel 7. Output SPSS Nilai Statistik Uji Secara Parsial.

$\begin{array}{llllll}\text { Variabel Bebas } & \text { Koefisien } & \text { S.E } & \text { Wald } & \text { Db } & \text { Sig. }\end{array}$

$\begin{array}{llllll}(1) & (2) & (3) & (4) & (4) & \text { (5) }\end{array}$




\begin{tabular}{lccccc}
\hline Tingkat Pendidikan KRT $\left.{ }^{*}\right)$ & 0,554 & 0,140 & 15,555 & 1 & $\mathbf{0 , 0 0 0}$ \\
\hline $\begin{array}{l}\text { Jumlah Anggota Rumah } \\
\text { Tangga }\end{array}$ & $-0,035$ & 0,039 & 0,776 & 1 & 0,378 \\
\hline $\begin{array}{l}\text { Pernah Mengalami Bencana } \\
\text { Alam }{ }^{*} \text { ) }\end{array}$ & 0,448 & 0,108 & 17,061 & 1 & $\mathbf{0 , 0 0 0}$ \\
\hline $\begin{array}{l}\text { Partisipasi Kegiatan } \\
\text { Kemasyarakatan }\end{array}$ & - & - & 16,298 & 2 & $\mathbf{0 , 0 0 0}$ \\
\hline $\begin{array}{l}\text { Partisipasi Kegiatan } \\
\text { Kemasyarakatan (sering) }\end{array}$ & $-0,045$ & 0,133 & 0,115 & 1 & 0,734 \\
\hline $\begin{array}{l}\text { Partisipasi Kegiatan } \\
\text { Kemasyarakatan (selalu) }{ }^{(*)}\end{array}$ & 0,422 & 0,126 & 11,237 & 1 & $\mathbf{0 , 0 0 1}$ \\
\hline $\begin{array}{l}\text { Klasifikasi Wilayah Tempat } \\
\text { tingal }\end{array}$ & 0,187 & 0,113 & 2,703 & 1 & 0,100 \\
\hline Akses Informasi $\left.{ }^{*}\right)$ & 0,345 & 0,121 & 8,149 & 1 & $\mathbf{0 , 0 0 4}$ \\
\hline Constant & $-0,794$ & 0,162 & 24,174 & 1 & $\mathbf{0 , 0 0 0}$
\end{tabular}

Sumber: Output SPSS

Variabel bebas yang berpengaruh signifikan terhadap status kesiapsiagaan rumah tangga dalam menghadapi bencana alam adalah variabel bebas yang mempunyai nilai signifikansi uji Wald kurang dari 0,05. Berdasarkan tabel diatas, terlihat bahwa nilai signifikansi dari variabel independen jumlah anggota rumah tangga, partisipasi kegiatan kemasyarakatan (kategori sering), dan klasifikasi wilayah tempat tinggal, lebih besar dari tingkat signifikansi 0,05, sehingga memberikan keputusan gagal tolak HO. Sedangkan variabel tingkat pendidikan KRT, pernah mengalami bencana alam, partisipasi kegiatan kemasyarakatan (kategori selalu), dan akses informasi memiliki nilai signifikansi yang lebih kecil dari tingkat signifikansi 0,05, sehingga memberikan keputusan tolak $\mathrm{H} 0$. Oleh sebab itu, dapat disimpulkan bahwa variabel yang signifikan memengaruhi status kesiapsiagaan rumah tangga dalam menghadapi bencana alam adalah variabel tingkat pendidikan kepala rumah tangga, pernah mengalami bencana alam, partisipasi kegiatan kemasyarakatan (kategori selalu) dan akses informasi. Sedangkan variabel jumlah anggota rumah tangga, partisipasi kegiatan kemasyarakatan (kategori sering) dan klasifikasi wilayah tempat tinggal tidak signifikan memengaruhi status kesiapsiagaan rumah tangga dalam menghadapi bencana alam.

\section{Interpretasi Odds Ratio}

Dari tabel 8. di bawah ini dapat dijelaskan kecenderungan dari masing-masing variabel yang memengaruhi status kesiapsiagaan rumah tangga dalam menghadapi bencana alam. 
Tabel 8. Output SPSS Odds Ratio.

\begin{tabular}{|l|c|l|}
\hline \multicolumn{1}{|c|}{ Variabel Signifikan } & $\begin{array}{l}\text { Odds } \\
\text { Ratio }\end{array}$ & \multicolumn{1}{c|}{ Interpretasi } \\
\hline \multicolumn{1}{|c|}{$(\mathbf{1})$} & $\mathbf{( 2 )}$ & \multicolumn{1}{c|}{$\mathbf{1 3}$} \\
\hline $\begin{array}{l}\text { Tingkat pendidikan } \\
\text { kepala rumah tangga }\end{array}$ & $\mathbf{1 , 7 4 0}$ & $\begin{array}{l}\text { Rumah tangga dengan tingkat pendidikan kepala rumah tangga } \\
\text { tinggi, 1,740 kali lebih siap dalam menghadapi bencana alam } \\
\text { dibandingkan rumah tangga yang tingkat pendidikan kepala } \\
\text { rumah tangganya rendah. }\end{array}$ \\
\hline $\begin{array}{l}\text { Pernah mengalami } \\
\text { bencana alam }\end{array}$ & $\mathbf{1 , 5 6 5}$ & $\begin{array}{l}\text { Rumah tangga yang pernah mengalami bencana alam, memilki } \\
\text { kecenderungan untuk siap 1,565 kali dibandingkan rumah tangga } \\
\text { yang belum pernah mengalami bencana alam. }\end{array}$ \\
\hline $\begin{array}{l}\text { Partisipasi kegiatan } \\
\text { kemasyarakatan(2) }\end{array}$ & $\mathbf{1 , 5 2 5}$ & $\begin{array}{l}\text { Rumah tangga yang selalu berpartisipasi dalam mengikuti } \\
\text { kegiatan kemasyarakatan, 1,525 kali lebih siap dibandingkan } \\
\text { rumah tangga yang tidak pernah/kadang-kadang berpartisipasi } \\
\text { dalam kegiatan kemasyarakatan. }\end{array}$ \\
\hline Akses informasi & $\mathbf{1 , 4 1 2}$ & $\begin{array}{l}\text { Rumah tangga dengan akses informasi baik, 1,412 kali lebih siap } \\
\text { dalam menghadapi bencana alam dibandingkan rumah tangga } \\
\text { yang memiliki akses informasi yang tidak baik. }\end{array}$ \\
\hline
\end{tabular}

\section{KESIMPULAN}

Berdasarkan hasil dan pembahasan yang telah dijelaskan sebelumnya, maka kesimpulan yang dapat diambil dari penelitian ini adalah rumah tangga di provinsi Jawa Tengah masih banyak yang belum siap dalam menghadapi bencana alam. Dimana, presentase rumah tangga yang siap dalam menghadapi bencana alam hanya sebesar 44,8 persen. Artinya dari 100 rumah tangga hanya 45 rumah tangga yang siap dalam menghadapi bencana alam. Tingkat pendidikan kepala rumah tangga, pernah mengalami bencana alam, partisipasi kegiatan kemasyarakatan, dan akses informasi merupakan variabel berpengaruh signifikan terhadap status kesiapsiagaan rumah tangga dalam menghadapi bencana alam. Tingkat pendidikan KRT merupakan vaiabel yang paling berpengaruh terhadap status kesiapsiagaan rumah tangga karena memiliki nilai odds ratio terbesar.

Berdasarkan kesimpulan diatas, maka saran yang dapat diberikan adalah, bagi rumah tangga agar lebih aktif terlibat di dalam kegiatan-kegiatan kemasyarakatan. Tujuannya agar rumah tangga dapat menjaring dan bertukar informasi terkait berbagai hal tentang bencana dengan anggota komunitas di lingkungan sekitar. Anggota rumah tangga juga harus lebih aktif untuk mencari informasi tentang bencana alam, seperti bahaya, tanda-tanda, cara menyelamatkan diri, dsb, sehingga dapat mengidentifikasi ancaman bahaya maupun kerentanan. Hal ini demi tercapainya tujuan dari pembangunan berkelanjutan, yang diantaranya untuk mengurangi jumlah korban terdampak, serta membangun kota dan komunitas yang kuat dan tangguh dalam menghadapi bencana alam. Selain itu, bagi peneliti selanjutnya, agar dapat melakukan penelitian kesiapsiagaan dengan menggunakan metode yang lebih mendalam seperti spasial maupun regresi logistik ordinal.

\section{DAFTAR PUSTAKA}

Ae, P. H. (2013). An Introduction to Logistic Regression : From Basic Concepts to Interpretation with Particular Attention to Nursing Domain. Journal of Korean Academy of Nursing, 43(2), 154-164.

Badan Pusat Statistik (BPS). (2014). Indikator Perilaku Peduli Lingkungan Hidup. https://www.bps.go.id/publication/2013/12/27/26e979dbdd579d7b6db6941d/indikator-perilaku-peduli-lingkunganhidup-2013.html

BNPB. (2014). Indeks Risiko Bencana Indonesia. http://inarisk.bnpb.go.id/irbi

BNPB. (2018). Tanggap Tangkas Tangguh Menghadapi Bencana. PDIH BNPB.

Brunie, A. (2007). Household Disaster Preparedness: Assessing the Importance of Relational and Community Social Capital (University of North Carolina).https://cdr.lib.unc.edu/concern/dissertations/ng451h70p

CRED \& UNISDR. (2017). Economic Losses, Poverty \& Disasters 1998-2017. https://www.cred.be/downloadFile.php?file=sites/default/files/CRED_Economic_Losses_10oct.pdf

Dokhi, M. et all. (2017). Social Capital and Disaster Preparedness in Indonesia: A Quantitative Assessment Through Binary Logistic Regression In Disaster Risk Reduction In Indonesia. https://doi.org/10.1007/978-3-319-54466-3_24

Hidayati, D. (2008). Kesiapsiagaan Masyarakat: Paradigma Baru Pengelolaan Bencana Alam di Indonesia. Kependudukan Indonesia, III(I), 69-84. https://doi.org/doites 
Hosmer, D. W. \& S. L. (2000). Applied Logistic Regression Second Edition. New York: John Wiley and Sons.

ISDR. (2005). Perkataan Menjadi Tindakan: Panduan untuk Mengimplementasikan Kerangka Kerja Hyogo. http://perpustakaan.bnpb.go.id/index.php?p=show_detail\&id=1641\&keywords=

Juha I. Uitto \& Rajib Shaw. (2016). Sustainable Development and Disaster Risk Reduction. (April 2019), $279-287$. https://doi.org/10.1007/978-4-431-55078-5_18

LIPI-UNESCO/ISDR. (2006). Kajian Kesiapsiagaan Masyarakat Dalam Mengantisipasi Bencana Gempa Bumi \& Tsunami. Jakarta: LIPI-UNESCO.

Prasiska, D. D. (2017). Analisis Mitigasi Bencana Alam Level Rumah Tangga di Indonesia. [Skripsi]. Sekolah Tinggi Ilmu Statistik. 